\title{
The Case of Walking Through in Mahmud Dervish Junior High School in Majd al-Kroom
}

\author{
Husein Saris \\ West University of Timisora, Timisora, Romania
}

\begin{abstract}
This study examined the process of leading a pedagogic change in the junior high school in the village of Majd al-Kroom in Northern Israel. The school adopted an educational initiative called "Walkthrough" which is a comprehensive internal evaluating tool operated in the school by the faculty. The tool includes focused regular observations within a defined period to examine a particular issue determined by the school. The research question was: How is the Walking Through as pedagogical tool perceived by the faculty and the school's management? To receive an answer to this question, the researcher had conducted a qualitative study based on teachers' interviews. The research findings suggested the following: School principal is a key personality in the implementation of any change. School principal is perceived as a pedagogic leader seeking ways to improve teachers' functioning. The aim of the "Walking Through" initiative is to improve the teaching quality by experiencing success. The "Walking Through" has direct and indirect influence on the organizational culture; objectivity, collegiality, cooperation, support, feedback, and assessment become part of the school's discourse. The main research conclusion is that school principals thrive to reach organizational and pedagogic excellence and gain experience via this school's experience.
\end{abstract}

Keywords: walkthrough, peers assessment, school principal as leading changes

A school principal is obliged on one hand to lead qualitative pedagogic processes and initiative, and on the other hand, to evaluate these processes and their results. Recently, there is a growing interest in an educational initiative called "Walkthrough". This initiative is perceived as an observation tool aiming to provide a reliable picture of the school's behavioral patterns and practices. It is based on serial short visits in the classes, focused on preselected practice that enables the principal to build himself as pedagogic leader and develop professional discourse with the faculty by identification of the faculty's strength points and motivating the staff to learn. According to Guttmann (2012), the organizational order of "Go \& Learn" facilitates a constant of learning and improvement process in the school.

Teachers and principals assessment is an important layer in the advancement of teaching and learning quality; therefore, the question how to construct it to insure its effectiveness concerns several countries across the world (Isoré, 2009; Sclafani, 2009), as well as in the Mckinsey Report (2007) which pointed out that the main factor affecting learning in the school is teachers' quality and that this factor is strengthening whenever the pressure to raise academic achievements.

Corresponding author: Husein Saris, Ph.D. student at Education Administration, MA in Educational Systems Management, West University of Timisora, Timisora, Romania; research field: educational leadership in the Arab sector in Israel. 
Peers assessment contains an in-built emphasis of planning and reflection; it exposes before the participants not only the products but also the techniques and the assessment process performed by the teacher and the peers. The process is as important as the findings of the assessment (Zariski, 1996). A study conducted by Dominick, Reilly, and McGourty (1997) revealed that the contribution for achievements improvement of the mere performance of peers' work assessment is not lesser than the contribution of the feedback the students received for their work.

Peers assessment is a common method in various types of organizations, and can be performed in various modes. It aims to create a change, overcome weaknesses, and replace them with strength. Walkthrough is not just another assessment tool; it is an independent tool whose aims are far from just an assessment; therefore, the school management, and the principal in particular, are responsible for the application of Walking Through in their school.

Walkthrough is a comprehensive assessment tool operating in the school and activated by the school own faculty. The Walkthrough is designed in a way that enables it to examine almost anything that occurs in the school: teachers' behaviors, teachers' initiatives, pupils' initiatives, work patterns, etc.

The origin of the Walkthrough is a managerial tool called Classroom Walkthrough developed in the USA that was meant to help school principals to increase their managerial effectiveness by going around in the school's premises and get closer familiarity and understanding of their organizations' interconnections and functioning. But it had been adapted to serve as a pedagogic practice tool comprising short rounds in classrooms to gather data on teaching and learning to enable the faculty to conduct pedagogic discourse on the basis of the data gathered.

Thus, we can conclude that Walking Through depends on the principal who should be leading and directing it. This leads the discussion to the principal's role.

According to Heifetz and Lewinski (2007), today, school management turned to be a private case of managing an organization; therefore, the principal's systemic view and the way he perceives a learning organization coping with a complex changing environment become of extreme importance. The principal is perceived as an educational leader; therefore, the literature refers to decisions he makes, his courage, and resourcefulness in coping with changing environments and leading a change.

In the following section, the researcher shall specify the tasks of a school principal in general, and his task leading a change in particular.

\section{The School Principal as Leading Changes}

Educational leadership focuses mainly on aspects of the principal's work aimed to advance the teachers' teaching and the pupils' learning. Pedagogic leadership can be classified into three dimensions: phrasing the aims and objectives of the school; coordinating supervision and evaluation of the curricula, teaching modes, and assessment; and nurturing learning climate.

Today, the role of school principal is highly complex due to several diverse, interdependent, and organizational processes in rapidly changing environment and circumstances. Thus, principals have to reach decisions in diverse issues when only time will tell whether they were the right decisions or not (Oreg \& Berzon, 2013; Katz, 2011).

There are a number of actions that characterize leadership able to maintain successes and change: identification of trends dominating the current educational reality; constant examination of the impact of these 
trends on the school's contents, methodologies, aims, and objectives; and constantly evaluating the school's status, conduct, and functioning in order to make the required adjustments (Duke, 2010).

\section{Introduction of Change: A Case Study}

\section{Study's Aim}

This study will investigate in depth the four-year process of leading a pedagogic change, which takes place in Majd al-Kroom Junior High School.

\section{Research Questions}

The main research question is: How is the issue of introduction and implementation of pedagogic changes, by means of Walkthrough, perceived by the school managements and teachers?

The secondary questions are:

(1) How do the teachers perceive the changes and innovations in general and the Walkthrough in particular?

(2) Does a fertile cooperation between the principal who leads this change and the teachers, which is a necessary condition for the realization of the school's aims and objectives, exist? Or is it possible that introducing a change of this magnitude in the school can raise resistance among the teachers who might speak it?

(3) Is the Walkthrough a change affecting all the organization culture components, suiting the existing norms and values, and contributing to all factors involved?

\section{Research Type}

This study is a case study, which, in this structure, is part of the category called "qualitative study" which is a study investigating phenomenon, an in-depth learning of a specific unit - an individual, an event, a program, organization, certain period, certain community, etc.

\section{Research Field}

The research took place in the Junior High School of Majd al-Kroom, a village located in Northern Israel. The school employs 85 teachers who teach a little over 1,000 pupils.

\section{Research Participants}

The study focused on seven teachers who were incorporated in the pedagogic committee that designed, constructed, and carried out the Walkthrough initiative in the school. These teachers were: the school principal - 44 year-old male, having six years on the job, a math teacher by training who holds an MA in management; deputy principal-39 year-old male, responsible for the pedagogic area and activation of the Walkthrough in the school, having five years on the job and holding an MA in teaching the Arabic language; and other five teachers: a science teacher, a special education teacher, a male geography teacher, a female Arabic teacher and social education coordinator, and a male Hebrew teacher.

\section{Research Tools}

(1) Classroom observations - performed quietly without participation. Comments and impressions were recorded on feedback forms.

(2) In-depth interview - meant to understand the experience of other people and the meaning they attribute to that experience. The interview had a part that referred to the introductions and the interviewee's perception of the Walkthrough initiative. 


\section{Data Analysis}

Levitski (2010) suggested four principles for analysis of qualitative study: proximity, theoretical sensitivity, continuity, and reflectivity. The researcher chose content analysis when the main strategy is constant comparison.

\section{Research Findings}

The findings will follow the research model in order to receive a comprehensive picture of the effect and the contribution of the Walkthrough initiative on the school and its various components. The findings were subdivided into three categories:

(1) A general assessment of the Majd al-Kroom Junior High School and the impact of the Walkthrough in particular;

(2) The difficulties and barriers confronted by the principal during the assimilation of the Walkthrough;

(3) The role of the school principal and the change that occurred in the school's organizational culture and values.

\section{Assessment as Part of the School's Organizational Culture}

Assessment is one of the core tasks of the school principal. It refers to all the educational areas in the school, as the principal is expected to assess teachers, achievements, etc.

Majd al-Kroom Junior High School is an organization that views assessment as an integral part of the organizational culture, language, and values. Teachers, both seniors and newcomers, appreciate the assessment and view it as an important tool to advance their work and the school's aims and objectives. According to a teacher of 20-year seniority, assessment increases the teacher's efficiency because the knowledge of being assessed motivates the teacher to invest in preparation and expansion of his knowledge regarding the subject matter.

Another teacher shares the view of the teachers mentioned above, but points out the time and quality factors. According to him, if and when assessment is performed correctly, it can certainly contribute to the teachers' work and help him/her achieve professionalism. In his view, the assessment performed in the school is right: It is controlled and it is also performed consistently. The teachers assessed do not feel that they are scrutinized in order to find fault; it aims to help you become a better teacher.

The school management emphasizes the importance of the assessment role in the school; the principal, whose role is to assess the teachers, the project leading team and his own functioning, says:

"Assessment is a very important part of my work; assessment enables me to see the overall picture of the school and learn where things could be improved and what has to be strengthened".

The deputy principal has a similar view:

"We promote various assessment processes in the school in order to constantly improve things; I, as a deputy principal, consider assessment as a major factor in our success".

The deputy principal appreciates the importance of assessment but he is also aware of possible dangers:

...if assessment is performed randomly without planning, it might cause distortions and harm the school; assessment should be clear and transparent, the person assessed has to know who assesses him and why and he should be given feedback in order to improve...

Not only the school management understands the possible pros and cons of assessment, other teachers are 
also aware of the possible danger of assessment and the fact that some teachers might perceive assessment as threatening.

\section{The Walkthrough as Perceived by Teachers of the School Studied}

The researcher examined the way that the management perceives the Walkthrough as part of the evaluation system of the school. The idea was to examine the perception of the principal and the deputy principal who lead the execution of the Walkthrough and therefore affect significantly the subject aspects and issues selected for examination.

The principal believes that the Walkthrough is a learning tool that enables the faculty to receive plenty of information about the faculty by the faculty. This information is highly relevant to school's life and to organizational and pedagogical processes that occur in the school. In his opinion, the main point is that the teachers will commit themselves to constant improvement, not necessarily in big steps; improvement can be gradual and slow, as long as it continues. The pupils will enjoy quality classes and the teachers will feel capable, as everyone knows, success begets success. In his opinion, although there are other initiatives, the Walkthrough is the most important initiative in the school. The principal says that he is proud to be part of a team that dared to be exposed and evaluated by other teachers. The team of this particular school managed to introduce and implement an educational initiative that does not exist even in the Jewish sector, and the schools that can and are ready to adopt this initiative are considerably few.

The deputy principal leads this initiative in the last three years. In his interview, he remarks that the Walkthrough is a very strong organizational tool; it can be adjusted to schools, but not always and not to all schools:

Walkthrough is a first class change; it concerns almost all the aspects of the school. Introduction of tools from the business world to school can be highly beneficial, but we have to be very careful; if Walkthrough which is essential observation of peers is not mutual, reliable, and absolutely transparent, there might be fear that such a tool will turn the school into a criticizing organization and cause an unpleasant atmosphere in the school.

Thus, the deputy principal points out the necessary conditions that must exist in the organizational culture of a school that considers to adopt tools similar to Walkthrough, which are: transparency, reliability, and mutuality.

The personal interviews yielded some interesting reflections regarding the Walkthrough effect: A veteran teacher said:

This gave me an opportunity to learn and expand my horizons. Who would have thought that after 30 years of teaching I will enter a class of a rookie teacher and learn from him about how to conduct a dialog and how to get the pupils to initiate?

Another teacher was thrilled with the opportunity to observe peers and to receive feedback from peers who observed her class; she emphasized the professional value of the Walkthrough:

"...it enables the teachers to constantly think and initiate, to come up with quality pedagogy".

Another teacher referred to the emotional aspect of the Walkthrough, she said that for her, it was an elevating experience; according to her, it gave the teachers the feeling of success of personal ability.

However, one of the research participants reported some difficulties at the beginning of the project; according to him, he did not like the idea of people entering the class to watch how he teaches. It intimidated him at first, and he had to adjust and accept, but eventually, he had realized that the information they gather 
was aimed to improve things and he began to go with it. It caused him to reflect on his methodology and to think how he can teach more effectively.

\section{Walkthrough: Intentional Change According to Cutter's Model}

Success in conducting an intentional change is combination of $10 \%$ knowledge of models and methods and $90 \%$ effort to introduce the change, lead it, and assimilate it in a way it will be sustained. John Cutter, an international expert on leadership of Harvard Business School, studies several projects: those that were a success story and those that failed. His book Leading Change (1996), which was a global best seller, includes an eight-stage formula for leading a change. It seems that the change implemented in the school we studied was planned according to these stages.

\section{Creating the Need for the Walkthrough Project}

According to the principal, ever since he was appointed school principal about seven years ago, his goal had been to bring the school to social, pedagogic, and organizational excellence, and with the willing cooperation of his management members and the faculty, he began to seek ways to reach this goal. After examination of several models and methodologies, he and his fellow management members began to bring to the teachers' lounge in school articles dealing with introduction of change and renovation. The idea that there may be examples out of options for improvement caught the attention of entire faculty; teachers began to seek material and e-mail from each other. The material received became the subject of discussions. The principal realized the interest in acquiring efficiency and willing of general atmosphere to learn and improve, and invited an external lecturer to discuss matters with the faculty. This meeting yielded criteria for good teaching and good teacher. The teachers wanted to share their experiences with their peers, and suggested that various teams will observe other teams or individuals at work.

The principal admitted that at first he was suspicious about the idea, because he thought that it might cause problems and tensions among the teachers, but eventually, he accepted the idea of Walkthrough, mainly because he realized that this particular model, adopted from the discipline of organizational management, is flexible and could be adopted after adjustment and modification for educational institution will take place. Thus, he and other management members had been convinced that this initiative is the right model to follow, since it is based on basic eight-stage structure that could be modified according to needs of the given organization:

The preparation began with discussions and suggestions within the management, then we assembled the teachers, and told them that we learned that this is a good initiative that had proved itself, but it needs modifications, and we asked for suggestions and ideas; the teachers began to raise ideas, and my deputy suggested that we ask some other teachers what will be the best way to promote this initiative. We reassembled after two weeks and after recording and processing the ideas and applied those we thought right on the Walkthrough, the team was ready to go for it.

The deputy principal explains the second phase of the change planning after the need for a change was established:

...at first, it was hard to recruit the teachers for this task. It was not a casual request like changing the class sitting order or changing mark components, we ask them something that can be construed as threatening; so we began to think how to turn a threat into opportunity. We managed to convince most of the teachers that the Walkthrough is the right way for us. We invited suggestions and ideas for implementation and we talked about it and discussed various aspects of the Walkthrough, until it became regular part of the organizational discourse.

Some teachers adopted the Walkthrough idea as an opportunity to learn, to watch peers at work and 
experience peers' feedback. Others admitted that at the beginning, they were not absolutely sure, but they experienced healthy curiosity and chose to cooperate.

Another teacher spoke about the already accomplished improvement of the school relations with the surrounding community. The school demonstrated success in certain areas, and there was a feeling that success will beget success; there was a good atmosphere among the teachers and a feeling of: "yes, we can", so there was no problem to support the intentional change.

\section{Setting the Walkthrough in Motion}

The researcher was able to glean from the interviews various methods and factors for setting the intentional change in motion. According to the principal, the application of the Walkthrough begins when the following conditions are present:

(1) Teachers receive evaluation of their work;

(2) Learn from successes;

(3) Knowledge and controlling the knowledge becomes a convincing key;

(4) Charismatic position holders, especially the principal and the deputy, the project leader;

(5) Organizational transparency.

The deputy principal emphasized the need for investment of efforts and energies to convince the teachers, receive their trust, and show confidence in their ability. The initiative succeeded because the teachers realized that the tool was aimed to improve their functioning as teachers and enabled them to internalize that and its usage was not meant to criticize anyone; the main objective of this learning tool is to better facilitate the learning processes of the pupils.

The interviews with other teachers revealed the following:

The leading team of a given project in school should:

(1) Before introducing an initiative, there is a need to make the teachers believe in its purpose;

(2) Find a civil pleasant way to convince the teachers that the chosen initiative will benefit the school;

(3) Allow them a choice to join or not to join the initiative;

(4) Enable them to participate in all the initiative's decisions and results;

(5) Let them see (or hear) educational successes of others.

One of the teachers sums up the way the Walkthrough applied in the school in these words:

"...I think that a shared vision is a tool to motivate people; there is a need to convince the teachers to believe that the given initiative is a step towards the realization of the school's vision".

Another teacher said that it is not simple to demand constant renewal from the teachers; the demands get more intricate and complex; so it has to be applied carefully to suit the conditions and circumstances present in the school in question. He also said that teachers can change only when the school climate and the general atmosphere are encouraging and supportive. Or, as he sums it up:

"If the Walkthrough was unsuitable to our school, and was not catered and modified to the needs of our pupils and our teachers, it would not have succeeded".

\section{Sustaining the Change-Maintaining the Walkthrough}

The research population pointed out that the Walkthrough was improved from one year to the next.

According to the principal, in the first year of applying the initiative, the team examined 10 different subjects; in the second year, they focused on three subjects; and in the third year, apart from maintaining the 
momentum, they concentrated on one additional subject throughout the academic year. The think team met regularly to figure out new ways to improve the school's performance. The Walkthrough findings had been published in the teachers' lounge and in the school's site; the teachers were photographed and reports of the Walkthrough success and the positive change in the school had been submitted to the Ministry of Education for recognition and educational prize consideration.

The importance of the Walkthrough has not reduced; on the contrary, it became part of the organizational language and culture affecting all aspects of the school.

One of the teachers interviewed mentioned the deputy principal's professional presentation of the Walkthrough recommendations and the extended studies the school organized for teachers who wanted to expand their horizons, and suggested that the teachers know that the Walkthrough enables them to make a difference and affect the school's policy.

A teacher who was a member of the implementing team emphasized that the important point was that the Walkthrough was not forced on the faculty, but had been gradually introduced. The team was not expecting the initiative to be assimilated at once; they were patient, and as in any new methodology, there had been occasions of try and error. The main thing was to think positively and be positive; the feedback was always constructive, even when errors had been observed. They always discussed quietly what they saw, and if the observed class was not good, they looked for creative ways to improve methodology without being harsh and judgmental.

A teacher who was skeptical or even somewhat intimidated by the idea of being observed by peers at the beginning of the Walkthrough application, perceived consistency and dedication to the cause, along with the collective sense of cooperation and sharing comprising the most important factors for assimilation of change; according to his account, the cooperation between the management and the teachers made the Walkthrough something they all do together, helped each other improve and cooperate with others for the benefit of the pupils and the school.

A teacher holding an MA in management and leadership thought that in order to assimilate change, the main thing is to remove objections; she said that she appreciates the management's decision not to force teachers to participate, allow them to choose whether or not to be part in this initiative, but simultaneously use strategy that stresses the idea that it is a school matter and therefore concerns everyone. She also praised the usage of factors like cooperation and mutuality, and the encouragement, positive motivation that made people think how they can improve their personal functioning and contribute to the general effort.

\section{The Principal's Role: “My Role Is to Hone Diamonds”}

The school principal speaks on his role as follows:

My role is to guide the teachers and make them believe in our vision. I soon realized that to accomplish the vision, we have to prepare the organizational culture of the school in a way that will enable absorption of changes in the teaching and management modes. The progress took off as soon as the school adopted the idea to become a learning organization, an approach that connects pedagogic and managerial processes. In addition, the school adopted the perception of learning from success as the main working principle; from each little success, we learned something. Successes of individual teachers were presented in the teachers' lounge, and attracted attention and encouragement. As the school is subdivided into circles and layers, my role is to support position holders and teachers. When we introduced the Walkthrough, I took part in the phrasing of the questionnaires and the observation team; however, I performed much of these duties by proxy, my deputy was the actual member of the observation team and a major factor in data gathering and analysis of the results. And what results he got! Absolutely fantastic! I want to enable each of my faculty members to develop according to his/her 
own pace, according to his/her own ability. Personally, I feel more like a coach than a manager; this is my role, the human capital in our organization is excellent, it's like a diamond that only needs honing.

The researcher asked the other interviewees how they perceive the role of a school principal in general and whether or not their principal fits the requirements.

One of the interviewees compares the role of the principal to that of a basketball coach, training a group how to achieve a common goal. Just as a coach has to get the best from his team, the principal has to get the best of his faculty. It requires dedication to the cause, warmth, sympathy, and positive energies. According to him, there are plenty of those in the school.

A teacher who is a kinesiology expert said that for her, the main role of the principal is to understand her needs and the needs of the other teachers. He has to be social:

Our school is under the jurisdiction of the Ministry of Education, the ministry is our employer and the principal is our leader. In my opinion, the role of the leader is to delegate authorities, to motivate people to think of better ways to act or handle a situation... he must be honest and transparent, I want to know what he really thinks of me, what he likes, and what he does not. I want him to show me that he is wise and knowledgeable.

One of the research participants, whose relations with the principal are inconsistent, thinks that a principal should not be an active part of such an initiative; since his presence "stresses" the teacher observed. He thinks that during the implementation of Walkthrough, the principal should support the activities from a distance and radiate confidence and success. It would be better if he will not be judgmental; it is uncomfortable to work with judgmental people, and he also expresses the opinion that criticism should be constructive.

Regarding the Walkthrough, this teacher observed that it can be a powerful tool in the hands of any principal or another organization manager. However, she pointed out that the principal of the school studied did not use the Walkthrough initiative to assume more control on the staff:

He always thought how he can improve its effectiveness and how to avoid turning it into hindrance. In my opinion, a school principal is required to have a comprehensive view of the entire system and waste no time on ego games.

\section{Discussion}

The aim of this study was to conduct in-depth investigation of introduction and implementation of pedagogic change process that takes place in a specific junior high school in Northern Israel in the last four years. This school, Mahmud Dervish Junior High School in Majd al-Kroom, adopted an educational initiative called Walkthrough, which is a comprehensive assessment tool activated in the school by the school's own faculty. The Walkthrough is able to examine almost everything that occurs in the school, teachers' behaviors, teachers' initiatives, pupils' initiatives, work patterns, etc. Recently, the school examined the dialog between teachers and pupils inside the classrooms. A Walkthrough can be defined as an upgraded type of peers' observation that looks into certain issue derived from the needs of the teachers at the school in order to lead to an organizational change by means of improving diverse, organizational, educational, and methodological aspects.

Unlike reforms that have been decided by the ministry or a relevant department and that the schools affected have to adjust themselves to the new approach or directives, whether or not it is viable and can benefit them, the Walkthrough initiative is an intentional, inwards directed change, initiated by the school's principal and its management in their pursuit for excellence. 
The idea behind the choice of this specific model is that an organization can change from within if the spirit and determination are there. The organization seeks improvement and it is not waiting for someone to do it for it, it takes charge to improve from within because it believes that it has the ability, the means, and the knowledge to do it.

Another important aspect of this initiative is that it has emerged in a school within the Israeli Arab society. Several scholars pointed out the gap between the Jewish educational system and the Arabic educational system. The reasons of this gap are numerous, and this discussion has no intention to explain them, just to acknowledge the fact. The point is that many schools in Israel, especially in the Arabic educational system, are used to receive educational initiatives from external sources. In many cases, such initiatives fail because they do not fit the school's culture and its organizational values, and they do not provide an answer to the needs of the school's population, teachers and pupils alike.

The researcher believes that the leadership of the Junior High School in Majd al-Kroom succeeds to change the functioning and the orientation of the school because they invest in the teachers; they want their teachers to develop professionally and the Walkthrough is a major instrument in reaching this objective.

Thus, the Walkthrough is not a superficial change aimed to impress someone; it brings about a profound and comprehensive change and this is the reason for its success.

Regarding the main research question, the study aims to answer the question how the issue of leading pedagogic change, in this case, the application of the Walkthrough, is perceived by the management, and how it is perceived by the teachers.

The findings indicate that the research population of this study perceives the initiative Walkthrough as an assessment tool that empowers the teachers and improves the school's organizational culture. The Walkthrough enables the teacher to be more efficient; both principal and the teachers interviewed emphasized the quality of the lessons given in the week the Walkthrough was activated. These successes lead to additional success; a teacher who performed a quality session that was observed by other teachers and had been appreciated by them, would "keep up the good work", and would most likely try to do even better next time.

So the main finding is that the Walkthrough is perceived by the principal, the management, and the faculty of the Junior High School in Majd al-Kroom as the most significant initiative that had been adopted and implemented in the school, as summed up by the principal:

"I believe that the Walkthrough is the most important initiative in the school; although there are other initiatives on the scene".

The literature supports the findings of this study that emphasized the positive influence of internal assessment on teaching quality. According to Guttmann (2012), the organizational regularity of the Walkthrough allows the existence of constant learning and improvement process in the school.

Guttmann is not the only one who appreciates the contribution of the Walkthrough; the assessment of teachers and principals process is an important stage in the advancement of teaching and learning quality and the query of building it in a constructive mode occupies several countries (Isoré, 2009; Sclafani, 2009). The issue was raised in several education related events when in many such occasions, it was pointed out that the main factor affecting learning in school is the teachers' quality, and that this factor is empowered whenever there are pressures to elevate achievements.

Rather than external pressure, from educational authorities, the surrounding community or from any other interested party, the Walkthrough creates internal pressure on teachers to elevate achievements; it is based on 
peers' feedback and managerial analysis of data obtained to reveal needs and suggest solutions. This pressure from within leads the teachers to find their inner quality in ways unconnected to resources and costs.

This finding is also supported by Duke (2010) who emphasized that the most important resources are not those purchased by money, but the commitment of teachers to never give up on any pupil, the willingness of principal to lead by personal example mode, and the support of parents and other social factors. Sustaining a change in the school is not a matter of luck, but the results of the efforts of skilled caring educators and the support and cooperation of a community that cares.

The second research question referred to the teachers' perception of pedagogic changes in general, and the Walkthrough in particular. The researcher's findings indicate that the Walkthrough became part of the organizational language. Teachers describe it as:

(1) It provides an opportunity to learn, and to expand one's horizons and change pre-set perception;

(2) It provokes the pursuit of excellence;

(3) It enhances collegiality, cooperation, and mutual learning;

(4) Feelings of success, of confidence on personal and organizational ability; it led to sharing of ideas and feeling of unity among the teachers;

(5) It had motivated teachers to reflect on their work prior to the initiative and during its activation.

These statements are compatible with the relevant literature that is elaborated on peers' assessment and emphasizes that it has an in-built planning and reflection. Pupils' academic achievements are the result of good teaching. It is well-known that when the achievements of the pupils are higher than expected, there is satisfaction among the teachers and satisfaction in the community.

Another question this study examined was how the managerial team prepared the faculty for the Walkthrough initiative, and how they handled objections.

Leadership is a popular subject of research, therefore, in this paper, the researcher would only mention basic features required and/or attributed to the leadership aspect of a school principal. According to Hen's (2007, inside Michaeli \& Fisher, 2010) report, a school principal is a professional leader; a school is first and foremost, a humane organization dealing in knowledge. Successful leader is a person who positively affects motivation and satisfaction of their workers and customers. The principal of the school studied perceives his staff as the most important resource that has to be invested in, encouraged, and guided. The teachers interviewed confirm this approach: They also emphasized the role of the principal as mentoring, leading, supportive, and encouraging.

Teachers said that the principal is the organizational leader; he has to be a man of vision, to recognize opportunities and lead us in the right direction. Nevertheless, most teachers expect the principal to be engaged in constructive assessment rather than a summing assessment.

Examination of the components of successful organizations (Sanji, 1995) includes the ability to adjust the local needs to self control, construct and establishment of a vision tailored to the internal and community needs, and the establishment of an organizational core connecting the organization and the reality.

Examination of these components in the Junior High School of Majd al-Kroom leads the researcher to the conclusion that the school studied is a successful organization, and that the modified version of the Walkthrough was tailored to the needs of the school. The principal outlines a vision which is adopted by the faculty; there is a professional managerial core supporting the principal and connecting the school's reality to its aims and objectives. 
Regarding dealing with objections, in fact, there was no significant objection to the Walkthrough, perhaps due to the fact that it was not forced; teachers were given the option to choose whether or not to take part in the initiative. The other reason why there was little objection was the mode of introduction: It was introduced gradually, discussed openly in the teachers' lounge, and constantly adjusted and modified.

It was found that the assimilation of the Walkthrough was not simple, and it was gradually applied and took almost four academic years before it became an integral part of the school's language and routine. Among other things, it changed the school's internal organizational values, caused radical change in the school's fundamental premises, and consolidated a new world view, due to change of perceptions compatible with the unique cultural requirements of school conduct in general, and the school in which it was applied in particular.

According to Rom (2008), when teachers participate in the development of assessment system that is catered to help them improve, there is a high likelihood that they will show more willingness to support and implement this system. The Walkthrough enables teachers to be responsible for their work, assume responsibility to their work and methodology, and participate in their assessment; this is why the assimilation of the change in this school became a success story. And as success begets success, the successful assimilation of this initiative and its positive results prepares the school's organizational culture to consider and apply more and more initiatives.

\section{Conclusions and Recommendations}

Reforms and changes in education have a considerable priority in several countries in the world, but regardless of increased expenditure on education and ambitious efforts invested, the performance of several educational systems has not been significantly improved for decades.

The Mckinsey Report (2007) listed three major factors for successful schools and successful educational system: attracting the right people to the profession; development that will make these people effective teachers; and insuring the ability of the system to provide the best quality education to each of its pupils.

To reach these goals, there is a need to invest in various parts of the system: from physical conditions, budget, and appropriate facilities to manpower, supervision, and incentives.

This study describes a specific case of leading a change in a junior high school of the Israeli Arab society. The school contains 1,100 pupils, and employs 90 teachers and reasonable number of administrative support and maintenance staff. The school has a high level of density, and the majority of its pupils come from a low to average socio-economic background.

There are not enough classrooms and lack of equipment, issues deriving of insufficient budget and resources allocation due to elongated discrimination of the minority sector and the periphery at large. Despite all the above mentioned, the school succeeded in the assimilation of a significant change affecting all the organizational circles and layers, teaching methodology, core values of the school's vision, and teaching quality.

The researcher agrees that a successful change derives from an organizational need, but in his opinion, such need has to be recognized and assessed before the entire organization is driven to do something about it. This leads the researcher to the conclusion that the school principal is the major stronger factor in the leading of this change. Therefore, the researcher suggests examining the steps he takes prior to introduction and implementation of changes to look into his leadership style and the models he adopts, and how he had managed to involve the entire faculty to follow him in his quest for excellence. 


\section{Recommendations}

(1) To continue the submission of ideas, and disseminate them throughout the organization;

(2) To look for other educational successes within the Arabic educational system, and find the ways and the means to encourage other schools to learn from successes of their peers and adopt the method or initiative they identify as good for them;

(3) To expand the research on changes in general;

(4) To study the field in order to find the right way of combining theory with practice;

(5) To encourage school principals to train intermediate leadership who will help him to lead changes in the school;

(6) To emphasize the importance of lessons learned from success, and use learning from success as internal working tool.

\section{References}

Balogun, J., \& Johnson, G. (2004). Organizational restructuring and middle manager sensemaking. Academy of Management Journal, 47(4), 523-549.

Dominick, P. G., Reilly, R. R., \& McGourty, J. W. (1997). The effects of peer feedback on team member behavior. Group and Organization Management, 22(4), 508-520.

Duke, D. (2010). The key to sustain successful school changes. Jerusalem: Avney Rosha Inst.

Guttmann, T. (2012). Tse Ulmad (Walkthrough). Jerusalem: Avney Rosha Inst.

Halverson, R., \& Smith, A. (2010). How new technologies have (and have not) changed teaching and learning in schools. Journal of Computing in Teacher Education, 26(2), 49-54.

Heifetz, R. A., \& Lewinski, M. (2007). Leadership test. Yediot Aharonot, Tel-Aviv.

Hen, D. (2007). Experimental schools: The source for educational innovation. Tel-Aviv University, Tel-Aviv.

Isoré, M. (2009). Teacher evaluation: Current practices in OECD countries and a literature review. OECD Education Working Paper No. 23.

Katz, I. (2011). Leadership in the eye of the storm. Retrieved from http://psychology.huji.ac.il/upload/articles/IsraelKatz.pdf

Levitski, N. (2010). Theory building process based on a narrative research. In L. Kesen and M. Krumer-Nevo (Eds.), Analysis of qualitative data (pp. 383-412). Beer Sheva: Ben Gurion University Publication.

Mckinsey Report. (2007). How the world's best-performing school systems come out on top. Retrieved from http://alamin99. wordpress.com/2008/02/22/mckinsey-report

Michaeli, N., \& Fisher, G. (2010). Change and improvement in education systems. An anthology of articles. Jerusalem: Branco Weiss Institute and Avney Rasha Institute.

Muijs, D., \& Lindsay, G. (2008). Where are we at? An empirical study of levels and methods of evaluating continuing professional development. British Educational Research Journal, 34(2), 195-211.

Oreg, S., \& Berzon, Y. (2013). Pedagogic leadership in Israel, evaluation and backing of pupils' achievements. Jerusalem: Avney Rosha Inst.

Rom, A. (2008). Internal assessment and teacher's self assessment. MUTAV Kaet, issue no. 1.

Sanji, P. (1995). The learning organization. Portland, Oregon: Productivity Press.

Sclafani, S. (2009). Evaluating and rewarding the quality of teachers: International practices. Paris: OECD Publications.

Zariski, A. (1996). Student peer assessment in tertiary education: Promise, perils and practice. In J. Abbott and L. Willcoxson (Eds.), Teaching and learning within and across disciplines (pp. 189-200). Perth: Murdoch University. 